\title{
Threshold analysis of particulate matter emissions from biological soil crusts and their proportion in total wind erosion
}

\author{
Yusong Wang ${ }^{1}$, Dandan Wang ${ }^{2}$, Xinxiao Yu ${ }^{1}$, Guodong Jia ${ }^{1}$, Xiaomin Chang ${ }^{1}$, Lele Sun ${ }^{3}$, \\ Pengfei Zheng ${ }^{1}$, and Yunxiao Qiu ${ }^{1}$ \\ ${ }^{1}$ Beijing Forestry University \\ ${ }^{2}$ China Institute of Water Resources and Hydropower Research \\ ${ }^{3}$ Yellow River Engineering Consulting Co Ltd
}

December 10, 2021

\begin{abstract}
The problem of farmland degradation and air pollution caused by wind erosion and particulate matter emissions is serious. Relying on biological soil crust coverage can effectively inhibit the production of wind erosion materials. However, recent studies have discussed the wind erosion and particulate matter emission processes separately and few studies analyzed both, clarifying the changes in the proportion of particulate matter emissions in the total wind erosion. Aiming at the typical farming-pastoral transition zone in the monsoon climate zone, this study used wind tunnels to analyze the wind erosion and particulate matter emissions of algae crusts and moss crusts for different wind speeds and coverage conditions. Results show that the effects of wind speed and coverage on the total wind erosion of biological soil crusts are similar. However, the emission of particulate matter is particularly sensitive to coverage of biological soil crusts. The proportion of particulate matter emissions in wind erosion decreases with increasing wind speed. According to the trend of the proportion with wind speed, the particle emission capacity of moss crust is directly proportional to the particle size and inversely proportional to the coverage. In contrast, the particle emission capacity of algae crust particles is proportional to the particle size, but the relationship with coverage is not regular. The results of this study can improve the knowledge of the relationship between wind erosion and particulate matter emissions and give relevant information for the management of wind erosion and particulate matter emissions.
\end{abstract}

\section{Introduction}

Wind erosion and particulate matter emissions are important and non-negligible reasons that cause landscape degradation and threaten human production and life (Borrelli et al., 2016; Deetz et al., 2016). Wind erosion causes a large amount of soil loss in farmland or forest land. Additionally, the emission of particulate matter caused by wind erosion carries a large amount of pesticides, microorganisms and heavy metal elements for migration (Van Pelt and Zobeck, 2007; Tatarko et al., 2020; Whicker et al., 2006). In recent years, large-scale accidents caused by wind erosion and particulate matter are no longer unusual (Li et al., 2018; Middleton, 2017). Effects of wind erosion and particulate matter emissions range from human health issues to global climate change (Goudie, 2014; Lambert et al., 2008). Influenced by the source of particulate matter emissions, previous studies focused on densely populated urban areas (Currie and Bass, 2008; Jiakai et al., 2016). However, farmland areas are also an important contribution area of particulate matter emissions (Korcz et al., 2009). Therefore, land degradation caused by wind erosion and particulate matter emissions should be analyzed in detail (Schmidt et al., 2017; Tatarko et al., 2020).

The factors influencing the natural wind erosion and particulate matter emission processes can be divided into physical and chemical factors, including: soil stability, soil properties, soil texture, soil density, soil water content, land cover, soil nutrients, etc. (Gillies et al., 2017; Hagen et al., 2010; Kohake et al., 2010; 
Zou et al., 2018). The soil particle size distribution is highly sensitive to the wind erosion process (Larney and Bullock, 1994). Previous studies have shown that wind erosion is prone to occur when the soil particle size ranges from $0.02 \mathrm{~mm}$ to $0.84 \mathrm{~mm}$. Particles with size between $0.05 \mathrm{~mm}$ and $0.5 \mathrm{~mm}$ are the most easily eroded particles (Chepil, 1955; Skidmore and Powers, 1982; Zou et al., 2018), sometimes even if the surface sand content is low, it may become a high PM10 emitter (Feng et al., 2011; Sweeney et al., 2011). When other factors remain constant, the material with large particle size and low density is more easily transported by wind (Zobeck et al., 2013), and soil density has less variability than soil texture (Kohake et al., 2010; Menut et al., 2013; Shahabinejad et al., 2019).

Previous studies have shown that as soil density increases, soil erodibility under wind conditions will decrease gradually (Campbell et al., 2002). Tillage and watering are main ways that rapidly change soil density and soil properties, affecting wind erosion and dust emission (Larney and Bullock, 1994). The surface aerodynamic parameters of different soil properties are variable, especially in arid and semi-arid areas. This difference has a profound impact on the wind erosion process (Campbell et al., 2002; Cheng et al., 2017; Zou et al., 2018).

The influence of soil nutrients is mainly reflected in the organic matter content. Non-agricultural soils increase soil organic matter through various methods, such as litter decomposition. Thus, as the organic matter increases, soil particles are aggregated and not easily dispersed (Mendez et al., 2006; Panebianco et al., 2016). Although agricultural soils have regular fertilization operations, the continuous cultivation process will inevitably continuously degrade the organic matter content in the soil, resulting in poor aggregation of soil particles and tendency to erosion (Acikgoz et al., 2017).

Irrigation can keep the soil surface moist and minimize wind erosion, but wind can use the evaporation process to continuously take away the water in the soil and reduce the cohesion of soil particles (Larney and Bullock, 1994). Therefore, the influence of soil water content changes is highly correlated with time.

The emission of particulate matter in wind erosion is directly related to the amount of wind erosion itself. The reduction of particulate pollution is a complex and non-linear process (Chang et al., 2019). Therefore, treatment from the source (such as vegetation or soil crust coverage) is a relatively efficient method. Biological soil crusts (BSCs), as one of the means of ground cover, can effectively inhibit wind erosion and impact significantly on the separation and transportation of particles of different sizes (Miralles-Mellado et al., 2011; Neuman et al., 1996). However, BSCs are also one of the sources of particulate matter emissions, which may have a higher level of microbial diversity, thereby endangering human health (Abed et al., 2012). Overall, it is relevant to study wind erosion and particulate matter emission under the BSC cover.

In order to prevent and control wind erosion and particulate matter emissions, physical, chemical and biological methods have been adopted. For instance, Schmidt et al. (2017) used the Index of Land Susceptibility to Wind Erosion (ILSWE) to quantify the elements of wind erosion, and assessed the wind erosion potential in Europe. In addition, Tian et al. (2018) used chemical solutions to consolidate the surface of the soil, which significantly increased the anti-erosion strength of the surface. Chang et al. (2021) suggested that windbreak forest belts effectively reduced wind erosion by $20 \%$ and significantly weakened PM10 emission concentration. Among all the prevention and control measures, biological measures are effective and nearly natural. However, most biological methods require a long growth period and have inherent limitations (Diouf et al., 1990; Maleki et al., 2016; McClure, 1998). Therefore, the use of BSCs for rapid growth and mulching is not only a more efficient wind erosion and particulate emission prevention and control method, but also provides a better growth basis for future vegetation succession. BSCs can effectively combine fine particles with each other and increase their threshold wind speed (Belnap and Gillette, 1998; Reynolds et al., 2001; Zhang et al., 2014). Previous studies have shown that mycorrhiza can significantly increase the degree of root colonization of plants during sowing, thereby decreasing the erodibility (Burri et al., 2013). Therefore, the use of BSCs to prevent wind erosion and particulate matter emission has good long-term benefits. Zhang et al. (2014) used dust fall and soil crust distribution to describe the stability of the wind and sand environment on a typical desert railway protection system, proving that it is beneficial to use soil crust to artificially improve the wind and sand environments. 
In order to understand the process of wind erosion and particulate matter emission, researchers more often use wind tunnel methods. Under natural conditions, changes in wind erosion and particulate emissions are more sensitive to height. Zobeck and Van Pelt (2006) suggested that the emission concentration of particulate matter in the height range of $2-5 \mathrm{~m}$ is $2-5$ times that in the height range of $5-10 \mathrm{~m}$. Generally speaking, bryophytes have a pseudo-leaf and pseudo-stem structure, and the formed moss crust is also relatively thick. Algae plants do not differentiate into leaves and stems. Thus, the algae crust is relatively flat (Belnap et al., 2013). Although the aerodynamic roughness length provided by the two types of biological soil crusts only measures millimeters or micrometers, their ability to prevent and control wind erosion and particulate matter emissions is still significant. The wind erosion material in the wind tunnel mainly moves horizontally, so the amount of wind erosion and the emission of particulate matter can be expressed by the horizontal flux (Panebianco et al., 2016), which has higher research efficiency. Bu et al. (2015) optimized the combination of soil water content, crust coverage, and vegetation coverage through experiments, and gave the most effective combination to reduce wind erosion. However, the soil water content is a constantly changing instantaneous value under the action of wind. Therefore, this combination method cannot be effectively used in practice. Copeland et al. (2009) used a wood-based long-strand material and agricultural straw to test wind erosion and particulate matter emissions. Their results show that wood materials have higher wind speed adaptability than agricultural straws, and wood materials have reduced wind erosion and particulate matter emissions by $90 \%$, under a wind speed of $11 \mathrm{~m} / \mathrm{s}$. Although straw cannot significantly reduce the total wind erosion, PM10 emissions have dropped by $75 \%$. In addition, Tatarko et al. (2020) conducted wind tunnel tests on 15 typical soils in the United States and concluded that abrasion coefficients and particulate matter emissions are more sensitive to soil types, soil textures and farming methods.

For the prevention and control of suspended dust generated by wind erosion, it is not only necessary to understand its source (Mirzamostafa et al., 1998; Hui et al., 2019), but also to clarify the content and proportion of particles of different sizes. Currently, studies have focused on the ratio of particles with different particle sizes (Cowherd, 2006; Feng et al., 2011; Li et al., 2015; Tatarko et al., 2020). Scholars have developed formulas for predicting particulate matter emissions (Tatarko et al., 2020), although some researchers believe that this empirical formula may lack universality (Sullivan and Ajwa, 2011).

Traditionally, in the research of farmland wind erosion and particulate matter emission control, BSCs have been studied as a prevention and control method. However, studies that can clarify the quantitative relationship between particulate matter emissions and wind erosion processes are not present in the literature (Li et al., 2015; Tatarko et al., 2020). This study will take two common BSCs and explore the thresholds of the proportion of particulate matter emissions during wind erosion, in order to provide an effective reference for the targeted management of wind erosion and particulate matter emissions.

\section{Materials and methods}

\subsection{Study area}

The area targeted by this research is the Zhangbei County in the Hebei Province, China (Figure 1; 40 03 ' to $41 \operatorname{deg} 27^{\prime} \mathrm{N}, 114 \mathrm{deg} 20^{\prime}$ to $\left.114 \mathrm{deg} 58^{\prime} \mathrm{E}\right)$. The study area has a mid-temperate continental monsoon climate, with an altitude ranging between $1600 \mathrm{~m}$ and $1800 \mathrm{~m}$, an annual average temperature of $3.2 \mathrm{deg}$, and an annual precipitation of approximately $300 \mathrm{~mm}$. Relatively dry conditions have caused vegetation degradation in this area (Sun et al., 2019). The study area has good wind resources and is the main route through which the northwest monsoon goes south in winter and spring. The annual average wind speed is approximately 6 $\mathrm{m} / \mathrm{s}$. In average, there are 30 days in a year with wind speeds exceeding the Near Gale (from international wind scale). The Zhangbei County belongs to the typical agro-pastoral transition zone. The soil conservation measures of the farmland are not perfect, which lead to soil wind erosion occasionally.

Figure.1 Location of the study area. The gray is the Hebei Province; the purple region is Zhangbei County; and the red star is Beijing.

\subsection{Biological soil crust sample collection}


In this study, the undisturbed soil collection method was used to collect algae and moss crust-covered soil. The size of the undisturbed soil collection box used in the study was $50 \mathrm{cmx} 20 \mathrm{cmx} 15 \mathrm{~cm}$. The four sides of the collection box were inserted into the soil as a whole to complete the fixation of the sample. The soil around the box was dug and the collection box was taken out containing the undisturbed soil. The box was closed at its bottom cover. The surface of the undisturbed soil sample was covered with a non-sticky plastic film to prevent soil damage and leakage. The soil sample assessed using a wind tunnel test. This study uses the point sampling frame to measure the BSC coverage of the soil (Li et al., 2010). Based on the 4 kinds of BSC coverage, in combination with the subsequent wind tunnel test, this study needs to repeat each measurement 3 times under 5 wind speed gradients. Therefore, 15 replicates of undisturbed soil samples for each coverage are ensured, setting up a statistically defensible experimental design. The classification of coverage is shown in Table 1.

Table 1. Coverage of biological soil crust

\subsection{Wind tunnel test}

\subsubsection{Wind tunnel description}

The wind tunnel was provided by the Laboratory of Wind and Sand Environment and Engineering of the Beijing Normal University. The wind tunnel has a total length of $34.4 \mathrm{~m}$. A high-power fan can adjust the wind speed between $1 \mathrm{~m} / \mathrm{s}$ and $40 \mathrm{~m} / \mathrm{s}$. The middle part of the wind tunnel is used to place experimental materials. It is surrounded by toughened glass and its cross-section is a rectangle of $0.6 \mathrm{mx} 0.8 \mathrm{~m}$. The pitot tube is used to measure the wind speed at different points in the tunnel. In the study of wind erosion and particulate matter emission, the abrader sand was not introduced into the wind flow upwind, but was directly measured the erosion amount of samples under different BSCs. In order to determine the amount of wind erosion, the tunnel uses an electronic scale (accuracy: $0.0005 \mathrm{~g}$ ) to weight the undisturbed soil collection box.

\subsubsection{Wind erosion and particulate matter emission measurement}

The collection box is placed in the middle of the wind tunnel. The plastic film was uncovered so that the surface of the BSC flushed with the bottom edge of the wind tunnel. Tape was used to seal the excess space around the collection box to prevent wind speed errors. The test subjects were divided into algal crust and moss crust. Each type of crust contained 4 kinds of coverage (see Table 1), and there were five wind speed gradients under each coverage $(8 \mathrm{~m} / \mathrm{s}, 10 \mathrm{~m} / \mathrm{s}, 12 \mathrm{~m} / \mathrm{s}, 14 \mathrm{~m} / \mathrm{s}$ and $16 \mathrm{~m} / \mathrm{s})$. Each wind speed gradient was blown and eroded for 10 minutes. It should be noted that each sample in this study only blows once at one wind speed, and no additional experiments are carried out. This removes the influence of different wind speed gradients on the same sample, which causes interference to the experimental results. The undisturbed soil collection box was weighed before each test and weighed again afterwards. The difference in weight was used as the total wind erosion amount of the BSC in this wind erosion test.

In order to determine the amount of particulate matter emitted during wind erosion of different BSCs, a particulate matter concentration observation device (Dustmate monitor, Turnkey, UK) was placed in the rear of the wind tunnel. Observations included the concentration of PM10, PM2.5 and PM1 $\left(\mu \mathrm{g} / \mathrm{m}^{3}\right)$, and the observation frequency was set to once every $30 \mathrm{~s}$.

\subsection{Data analysis}

The wind erosion material in the wind tunnel mainly moved horizontally. Thus, the amount of wind erosion and particulate matter emissions can be expressed in a unified horizontal direction (Panebianco et al., 2016). Affected by the BSC coverage, the amount of wind erosion produced in this research was relatively small. Thus, a high-precision electronic scale was used to measure wind erosion. The total amount of wind erosion was expressed as the difference in weight between the undisturbed soil collection box before and after the test. To calculate the proportion of particulate matter emissions in the total wind erosion, the particulate matter concentration was converted to the particulate matter mass, according to the specifications of the 
wind tunnel, using the following formula:

$$
m=\frac{C \times v \times t \times 0.6 \times 0.8}{1000000}
$$

where $m$ is the mass of particulate matter (in grams); $C$ is the emission concentration of particulate matter $\left(\mu \mathrm{g} / \mathrm{m}^{3}\right) ; v$ is the wind speed $(\mathrm{m} / \mathrm{s}) ; t$ is the blowing time $(\mathrm{s})$; and 0.6 and 0.8 are the height and width at the middle of the wind tunnel $(\mathrm{m})$, respectively. In order to consider the importance of the influencing factors, this study carried out a linear regression fitting for wind speed, coverage, wind erosion and particulate emissions, and standardized the coefficients as follows:

$$
B_{i}=b_{i} \times \frac{S_{i}}{S_{j}}
$$

where $B$ is the standardization coefficient; $b$ is the unstandardized coefficient; $S$ is the standard deviation; $i$ is the independent variable; and $j$ is the dependent variable.

The linear fitting and coefficient standardization methods used in this study were completed with SPSS 25. Data analysis was completed with Microsoft Excel 2019 and the drawing using Sigmaplot 12.5.

\section{Results}

\subsection{Influence of wind speed and coverage on the wind erosion of biological soil crusts}

In the natural environment, there are many factors that affect the growth and development of BSCs and their ecological contribution. In this control experiment, the largest influencing factors on the amount of wind erosion of BSCs are wind speed and coverage. From Figure 2, a clear influence of wind speed and coverage on the amount of wind erosion can be seen. The amount of wind erosion of algae crust and moss crust increases with increasing wind speed, and decreases with increasing coverage. Comparing the two BSCs, the change in the algae crusts is relatively stable, while the moss crusts have abrupt changes in wind erosion under coverage between $25 \%$ and $50 \%$ or wind speeds of about $12 \mathrm{~m} / \mathrm{s}$. The above phenomenon shows that the ability of different BSCs to consolidate soil and sand is significantly different.

Figure 2. The relationship between wind erosion, wind speed and coverage of BSCs. (The color from dark to light indicates the amount of wind erosion from small to large. The span of wind erosion produced by the different BSCs is different, which is reflected in the legend of this figure.)

Through the control of wind speed and coverage, the linear regression equations of wind speed, coverage and wind erosion under two kinds of BSC conditions were established respectively, and the importance of influencing factors was judged according to the standardized coefficients (Table 2). The linear regression fit of the two BSCs is good. Among the factors that affect the amount of wind erosion of algae crusts, the coverage (0.67) is stronger than wind speed (0.65), and among the factors that affect the amount of wind erosion of moss crusts, the coverage (0.53) is weaker than wind speed (0.58). The influence of the two factors is similar, which proves that in the process of windbreak and sand fixation, not only must the wind speed be reduced, but also the surface coverage must be ensured to reach the standard. The best effect of suppressing wind erosion can be achieved considering both factors.

Table 2. Regression equations of wind erosion of biological soil crust

\subsection{Influence of wind speed and coverage on particulate emissions of biological soil crusts}

This study further analyzed the emission of particles of different sizes and their relationship with wind speed and coverage under different BSC conditions. Figure 3 shows the influence process of wind speed and coverage on total suspended particulate matter, PM10, PM2.5, and PM1 emissions for algae crust. All particulate matter emissions increase with increasing wind speed and decrease with increasing cover degree. 
From the axial color change in the figure, the horizontal axis (coverage) has a larger change span, and the vertical axis (wind speed) has a smaller change span.

Figure 3. Relationship between particulate emissions size, wind speed and coverage of algae crusts. (The color from dark to light indicates the emission of particulate matter from small to large. There are differences in the emission of particles of different sizes, which is reflected in the legend of this figure.)

Similarly, for moss crust, the influence of wind speed and coverage on total suspended particulate matter, PM10, PM2.5, and PM1 emissions, is shown in Figure 4. All particulate matter emissions increase with increasing wind speed and decrease with increasing coverage. From the axial color change in Figure 3, the horizontal axis (coverage) has a larger change span, and the vertical axis (wind speed) has a smaller change span. The same behavior exhibited by the two BSCs proves that the degree of influence of coverage is greater than wind speed for particulate emissions. In order to quantify this result, we also established linear regression equations for the particulate emission of different particle sizes, wind speed and coverage under different BSC conditions (Table 3). The fitting effect of the particulate emission, wind speed and coverage of the two types of BSCs is good. Through the method of coefficient standardization, it can be seen that the influence of coverage on the dust emission is always higher than the wind speed.

Figure 4. Relationship between particulate emissions, wind speed and coverage of moss crusts. (The color from dark to light indicates the emission of particulate matter from small to large, respectively. There are differences in the emission of particles of different sizes, which is reflected in the legend of this figure.)

Table 3. Regression equations of particulate emissions of biological soil crust, where $\mathrm{R}$ represents goodness of fit, and $\mathrm{P}$ represents significance.

\subsection{The proportion of particulate emissions from biological soil crusts in the amount of wind erosion}

Particulate emissions are an important part of wind erosion materials, and clarifying the threshold of the proportion of particulate emissions in the amount of wind erosion will be beneficial to the deployment of targeted measures in the control of regional soil erosion. First, it is clear that the emissions of particulate matter of various sizes are directly related to the amount of wind erosion: the greater the amount of wind erosion, the greater the emission of particulate matter. The change of the amount of wind erosion is closely related to the wind speed and coverage (see Figure 5). Although the overall particulate emissions increase with increasing wind speed and decrease with increasing coverage, the amount of wind erosion also changes accordingly. Thus, proportion of particulate emissions in the amount of wind erosion has its own characteristics.

Figure 5. Distribution of particulate emissions in the corresponding wind erosion. The masses of wind erosion, PM10, PM2.5 and PM1 are overlapped under the same coverage $(1,2,3$, and 4$)$ and wind speed $(8,10,12,14$, and $16 \mathrm{~m} / \mathrm{s})$, to show the distribution and changes of particles of different sizes in the wind erosion.

The proportion of different particle size emitted by different BSCs under different coverage and wind speed in the corresponding wind erosion amount is not only inversely proportional to wind speed, but also inversely proportional to coverage (see Table 4). This phenomenon is inconsistent with the above-mentioned wind erosion and particulate emission behaviors. For moss crusts, for coverage $<25 \%$, the proportion varies with wind speed between $4.91 \%$ and $55.91 \%$; for coverage between $25 \%$ and $50 \%$, the variation range of the proportion with wind speed is $4.08 \%$ to $30.25 \%$; for coverage between $50 \%$ and $75 \%$, the variation range of the proportion with wind speed is $1.19 \%$ to $21.65 \%$; for coverage $>75 \%$, the variation range of the proportion with wind speed is $0.60 \%$ to $9.85 \%$.

For algae crust, for coverage $<25 \%$, the variation range of the proportion with wind speed is $8.80 \%$ to $29.16 \%$; for coverage between $25 \%$ and $50 \%$, the variation range of the proportion with wind speed is $3.26 \%$ to $28.01 \%$; for coverage between $50 \%$ and $75 \%$, the variation range of the proportion with wind speed is $7.15 \%$ to $45.97 \%$; for coverage $>75 \%$, the variation range of the proportion with wind speed is $0.72 \%$ to $11.70 \%$. In 
wind-eroded areas, the wind speed is changeable, and the ground cover will not change significantly without man-made influence. Therefore, this article only gives the threshold range of the change in the proportion of particulate emissions in wind erosion with wind speed under the same coverage conditions.

Table 4. The proportion of particulate emissions in the corresponding wind erosion, where $\mathrm{C}$ represents coverage type; WS represents wind speed; WE represents wind erosion; and SD represents standard deviation

\subsection{Particulate emission capacity of different biological soil crusts}

According to the principle of aerodynamics, the magnitude of wind speed will always drive changes in wind erosion and particulate matter emissions. From the above results, it can be seen that as the wind speed increases, the gap between the increase in wind erosion and the increase in particulate matter emissions increases, resulting in an inverse relationship between proportion and wind speed. When increasing wind speed, if the proportion of particulate emissions in the amount of wind erosion decreases slowly, it can be determined that this BSC has relatively strong particulate emissions under the corresponding coverage conditions. Conversely, if this proportion decreases rapidly with the wind speed, it can be considered that the BSC has a relatively weak particulate emission capacity under the corresponding coverage conditions. This study performed a linear fitting of the proportion of the emission of particles of different sizes in the wind erosion with the change of wind speed under the same coverage condition. The slope quantifies the particulate emission capacity of BSCs, as shown in Figure 6. For moss crusts, the emission capacity of particulate matter is directly proportional to particle size and inversely proportional to coverage. For algae crusts, although the emission capacity is proportional to particle size of the particulate matter, the relationship with coverage is not regular. It is embodied that PM10 has the strongest emission capacity for coverage between 50\% and 75\%. PM2.5 and PM1 have the strongest emission capacity for coverage between $25 \%$ and $50 \%$. The effective quantification of the emission capacity of particulate matter of different sizes can make control measures more targeted. The abnormal results of algae crust may be related to the physical properties of the soil. In general, the conditions of low soil bulk density, high porosity, and high water storage capacity lead to the development of biological soil crust. Otherwise, it is easy for the soil hardening phenomenon to occur. According to the morphological characteristics of the two biological soil crusts, algae crusts are flat and have less water conservation ability than moss crusts (Belnap et al., 2013). Therefore, under the condition of low coverage, the open space around the algal crust develops into a smooth and hard physical crust after precipitation (Sanders et al., 1986). The structure of the physical crust is compact and stable, and it will not cause a lot of wind erosion and particulate matter emission without external force damage. However, the over developed physical crust does not lead to vegetation succession and ecosystem restoration.

Figure 6. Particulate emission capacity of different biological soil crusts

\section{Discussion}

4.1 Effects of coverage and wind speed on wind erosion and particulate matter emission of biological soil crusts

There are many factors affecting wind erosion and particulate matter emissions in the natural environment. Although the use of BSCs to cover the ground has a significant effect, being human damage the largest influencing factor (Neff et al., 2008). In this study, the areas covered by BSCs belong to areas with low population density, so wind speed and coverage have become the biggest factors affecting the wind erosion of BSCs and particulate matter emissions (Hong et al., 2020). Comparing and analyzing the factors influencing wind speed and coverage in Table 1 and Table 2, the influence of wind speed and coverage on the amount of wind erosion is similar, but the degree of influence on particulate matter emissions is quite different. Specifically, the influence of coverage is stronger than wind speed, and as the particle size decreases, the greater the influence of coverage and smaller the influence of wind speed, as shown in Figure 7. This phenomenon indicates that for BSCs, coverage is more important than wind speed, which is closely related

to the nature of BSCs. Zou et al. (2018) summarized previous studies indicating that particles with a size of $0.05 \mathrm{~mm}$ to $-0.5 \mathrm{~mm}$ are most likely to be eroded. The BSC can aggregate small particles in this size range 
to form more stable large soil particles through the cementation and adhesion of fungal hyphae (Eldridge and Greene, 1994). Xie et al. (2007) also believed that the biomass of BSCs is closely related to its erosion resistance. In addition, Spagnuolo et al. (2013) argue that the surface of moss has a strong ability to adsorb particles, and some of the particles with very small diameters can even interact with moss cells. Thus, moss can become an environmental indicator. Microbes in algae crusts have similar functions (Bailey et al., 1973). The previous studies can prove that the structure and properties of BSCs are more likely to affect the process of wind erosion and particulate matter emission. Therefore, under the assumption of less human interference, the surface particulate matter emissions of BSCs are more sensitive to coverage, followed by wind speed.

Figure7. Influence of wind speed and coverage in particulate matter emission

\subsection{Threshold analysis of the proportion of particulate matter emissions in wind erosion}

The emission of particulate matter in the natural environment is mainly caused by wind. Under the influence of human activities in farmlands, when the crust is destroyed, particulate matter emission will increase significantly (Hoffmann and Funk, 2015). The change in the proportion of particulate matter emissions in the amount of wind erosion is closely related to the wind speed (Wiggs and Holmes, 2011). Zhou et al. (2020) showed that when the wind speed ranges between $6 \mathrm{~m} / \mathrm{s}$ and $-7 \mathrm{~m} / \mathrm{s}$, the dust emission flux can account for $23.60 \%$ to $26.58 \%$ of the total wind erosion. It reaches the maximum value, when the wind speed exceeds approximately $12 \mathrm{~m} / \mathrm{s}$. and the proportion of dust emission flux will be less than $1 \%$. Similar conclusions have been obtained in this study. Table 3 shows that under low wind speed conditions, the proportion of particulate matter emissions is the largest. This is because for low wind speeds it is difficult to transport the larger soil particles in the BSC, but reach the threshold wind velocity for small particles. Therefore, the proportion of particulate matter emissions in this stage is the largest in the total wind erosion. When the wind speed gradually increases, the soil with a larger particle size will be carried by the wind and become part of the total wind erosion. At this point, the soil particles with a large particle size become the main part of the total wind erosion. If more particulate matter is to be emitted, a process of mechanical crushing of large-diameter soil particles is required. However, the soil particles in the BSC are structurally stable and not easily broken under the action of microorganisms. As a result, the proportion of particulate matter emissions decreases as the wind speed increases.

Based on the amount of particulate matter emissions in the total amount of wind erosion, the amount of wind erosion can be effectively used to estimate particulate matter emissions (Alfaro et al., 2004). The correlation between the particulate matter emissions and wind erosion can effectively predict wind erosion and particulate matter emissions events (Saxton et al., 2000). BSCs can effectively inhibit wind erosion. Thus, it is relatively difficult to obtain observational data on the amount of wind erosion of BSCs. However, the concentration of particulate matter emitted from the surface can be measured by instruments, which is relatively easy to obtain. Therefore, it is a rare but feasible method that uses the particulate matter emission of BSCs to calculate wind erosion amount. In this calculation process, the threshold value of the proportion of particulate matter emission in wind erosion is the parameter to be defined.

\section{Conclusions}

This research analyses the common algae and moss biological soil crusts in the typical farming-pastoral ecotone. Using wind tunnel tests, the effects of wind speed and coverage on wind erosion and particulate matter emissions were studied and the relationship between particulate matter emission and wind erosion was analyzed. From the perspective of wind erosion, the influence of wind speed and coverage is similar. However, from the perspective of particulate matter emissions, the influence of coverage is always higher than wind speed, which is determined by the structure and nature of the biological soil crust itself. The proportion of particulate matter emitted from biological soil crusts in the amount of wind erosion has a significant behavior. Although the overall particulate matter emissions increase with increasing wind speed, the proportion of particulate matter emissions in the wind erosion is inversely proportional to the wind speed and coverage due to the corresponding changes in the amount of wind erosion. According to the trend 
of the proportion with wind speed, the particle emission capacity of moss crust is directly proportional to the particle size and inversely proportional to the coverage. The particle emission capacity of algae crust is proportional to the particle size, but its relationship with coverage is not regular. The results of this study can be relevant for the control of wind erosion and particulate matter emissions.

\section{Acknowledgements}

We are grateful for the grants from the National Key Research and Development Program of China (2016YFC0500802) (China) and from the Beijing Municipal Education Commission (CEFF-PXM2019_000099) (China).

\section{Declaration of competing interest}

The author declares that the publication of this scientific paper has no conflict of interest.

\section{References}

Abed, R.M., Ramette, A., Hübner, V., De Deckker, P., De Beer, D., 2012. Microbial diversity of eolian dust sources from saline lake sediments and biological soil crusts in arid Southern Australia. FEMS microbiology ecology 80, 294-304.

Acikgoz, S., Anderson, S., Gantzer, C., Thompson, A., Miles, R., 2017. 125 Years of soil and crop management on Sanborn field: Effects on soil physical properties related to soil erodibility. Soil Science 182, 172-180.

Alfaro, S.C., Rajot, J.L., Nickling, W., 2004. Estimation of PM20 emissions by wind erosion: main sources of uncertainties. Geomorphology 59, 63-74.

Bailey, D., Mazurak, A.P., Rosowski, J.R., 1973. AGGREGATION OF SOIL PARTICLES BY ALGAE 1. Journal of Phycology 9, 99-101.

Belnap, J., Gillette, D.A., 1998. Vulnerability of desert biological soil crusts to wind erosion: the influences of crust development, soil texture, and disturbance. Journal of arid environments 39, 133-142.

Belnap, J., Lange, O.L., 2013. Biological soil crusts: structure, function, and management, 150. Springer Science \& Business Media.

Borrelli, P., Panagos, P., Ballabio, C., Lugato, E., Weynants, M., Montanarella, L., 2016. Towards a PanEuropean Assessment of Land Susceptibility to Wind Erosion. Land Degradation \& Development 27, 10931105 .

Bu, C., Zhao, Y., Hill, R.L., Zhao, C., Yang, Y., Zhang, P., Wu, S., 2015. Wind erosion prevention characteristics and key influencing factors of bryophytic soil crusts. Plant and soil 397, 163-174.

Burri, K., Gromke, C., Graf, F., 2013. Mycorrhizal fungi protect the soil from wind erosion: a wind tunnel study. Land Degradation \& Development 24, 385-392.

Campbell, D.R., Lavoie, C., Rochefort, L., 2002. Wind erosion and surface stability in abandoned milled peatlands. Canadian Journal of Soil Science 82, 85-95.

Chang, X., Sun, L., Yu, X., Jia, G., Liu, J., Liu, Z., Zhu, X., Wang, Y., 2019. Effect of windbreaks on particle concentrations from agricultural fields under a variety of wind conditions in the farming-pastoral ecotone of northern China. Agriculture, Ecosystems \& Environment 281, 16-24.

Chang, X., Sun, L., Yu, X., Liu, Z., Jia, G., Wang, Y., Zhu, X., 2021. Windbreak efficiency in controlling wind erosion and particulate matter concentrations from farmlands. Agriculture, Ecosystems \& Environment $308,107269$.

Cheng, H., Liu, C., Li, J., Zou, X., Liu, B., Kang, L., Fang, Y., 2017. Wind erosion mass variability with sand bed in a wind tunnel. Soil and Tillage Research 165, 181-189. 
Chepil, W., 1955. Factors that influence clod structure and erodibility of soil by wind: IV. Sand, silt, and clay. Soil Science 80, 155-162.

Copeland, N., Sharratt, B., Wu, J., Foltz, R., Dooley, J., 2009. A wood-strand material for wind erosion control: Effects on total sediment loss, PM10 vertical flux, and PM10 loss. Journal of environmental quality 38, 139-148.

Cowherd, C., 2006. Background document for revisions to fine fraction ratios used for AP-42 fugitive dust emission factors. Prepared by Midwest Research Institute for Western Governors Association, Western Regional Air Partnership, Denver, CO.

Currie, B.A., Bass, B., 2008. Estimates of air pollution mitigation with green plants and green roofs using the UFORE model. Urban Ecosystems 11, 409-422.

Deetz, K., Klose, M., Kirchner, I., Cubasch, U., 2016. Numerical simulation of a dust event in northeastern Germany with a new dust emission scheme in COSMO-ART. Atmospheric Environment 126, 87-97.

Diouf, B., Skidmore, E., Layton, J., Hagen, L., 1990. Stabilizing fine sand by adding clay: laboratory wind tunnel study. Soil technology 3, 21-31.

Eldridge, D., Greene, R., 1994. Microbiotic soil crusts-a review of their roles in soil and ecological processes in the rangelands of Australia. Soil Research 32, 389-415.

Feng, G., Sharratt, B., Wendling, L., 2011. Fine particle emission potential from loam soils in a semiarid region. Soil Science Society of America Journal 75, 2262-2270.

Gillies, J.A., Nickling, W.G., Nikolich, G., Etyemezian, V., 2017. A wind tunnel study of the aerodynamic and sand trapping properties of porous mesh 3-dimensional roughness elements. Aeolian Research 25, 23-35.

Goudie, A.S., 2014. Desert dust and human health disorders. Environment International 63, 101-113.

Hagen, L.J., Pelt, S.V., Sharratt, B., 2010. Estimating the saltation and suspension components from field wind erosion. Aeolian Research 1, 147-153.

Hoffmann, C., Funk, R., 2015. Diurnal changes of PM10-emission from arable soils in NE-Germany. Aeolian Research 17, 117-127.

Hong, C., Chenchen, L., Xueyong, Z., Huiru, L., Liqiang, K., Bo, L., Jifeng, L., 2020. Wind erosion rate for vegetated soil cover: A prediction model based on surface shear strength. Catena 187, 104398.

Hui, H., Songyan, Jiang., Hu, Sheng., You, Zhang., Xuewei, Liu., Ling, Zhang., Zengwei, Yuan., Tianming, Chen., 2019. A high spatial-temporal resolution emission inventory of multi-type air pollutants for Wuxi city. Journal of Cleaner Production 229, 278-288.

Jiakai, L., Lichun, M., Lijuan, Z., Yilian, Y., Jiatong, L., Dongdong, Q., Zhenming, Z., Jinglan, L., 2016. Removal efficiency of particulate matters at different underlying surfaces in Beijing. Environmental Science\&Pollution Research 23, 408-417.

Kohake, D.J., Hagen, L.G., Skidmore, E.L., 2010. Wind Erodibility of Organic Soils. Soil Science Society of America Journal 74, 250-257.

Korcz, M., Fudała, J., Kliś, C., 2009. Estimation of wind blown dust emissions in Europe and its vicinity. Atmospheric Environment 43, 1410-1420.

Lambert, F., Delmonte, B., Petit, J.R., Bigler, M., Kaufmann, P.R., Hutterli, M.A., Stocker, T.F., Ruth, U., Steffensen, J.P., Maggi, V., 2008. Dust-climate couplings over the past 800,000years from the EPICA Dome C ice core. Nature 452, 616-619.

Larney, F.J., Bullock, M.S., 1994. Influence of soil wetness at time of tillage and tillage implement on soil properties affecting wind erosion. Soil and Tillage Research 29, 83-95. 
Li, H., Tatarko, J., Kucharski, M., Dong, Z., 2015. PM2. 5 and PM10 emissions from agricultural soils by wind erosion. Aeolian Research 19, 171-182.

Li, J., Kandakji, T., Lee, J.A., Tatarko, J., Collins, J.D., 2018. Blowing dust and highway safety in the southwestern United States: Characteristics of dust emission "hotspots" and management implications. Science of The Total Environment 621, 1023-1032.

Li, X.R., He, M.Z., Zerbe, S., Li, X.J., Liu, L.C., 2010. Micro-geomorphology determines community structure of biological soil crusts at small scales. Earth Surface Processes and Landforms 35, 932-940.

Maleki, M., Ebrahimi, S., Asadzadeh, F., Tabrizi, M.E., 2016. Performance of microbial-induced carbonate precipitation on wind erosion control of sandy soil. International journal of environmental science and technology 13, 937-944.

McClure, B., 1998. Policies related to combating desertification in the United States of America. Land Degradation \& Development 9, 383-392.

Mendez, M.J., Oro, L., Panebianco, J.E., Colazo, J.C., Buschiazzo, D.E., 2006. Organic carbon and nitrogen in soils of semiarid Argentina. Journal of soil and water conservation 61, 230-235.

Menut, L., Pérez, C., Haustein, K., Bessagnet, B., Alfaro, S., 2013. Impact of surface roughness and soil texture on mineral dust emission fluxes modeling. Journal of Geophysical Research Atmospheres 118, 65056520.

Middleton, N.J., 2017. Desert dust hazards: A global review. Aeolian Research 240, 53-63.

Miralles-Mellado, I., Cantón, Y., Solé-Benet, A., 2011. Two-dimensional porosity of crusted silty soils: Indicators of soil quality in semiarid rangelands? Soil Science Society of America Journal 75, 1330-1342.

Mirzamostafa, N., Stone, L., Hagen, L., Skidmore, E., 1998. Soil aggregate and texture effects on suspension components from wind erosion. Soil Science Society of America Journal 62, 1351-1361.

Neff, J., Ballantyne, A., Farmer, G., Mahowald, N., Conroy, J., Landry, C., Overpeck, J., Painter, T., Lawrence, C., Reynolds, R., 2008. Increasing eolian dust deposition in the western United States linked to human activity. Nature Geoscience 1, 189-195.

Neuman, C.M., Maxwell, C.D., Boulton, J.W., 1996. Wind transport of sand surfaces crusted with photoautotrophic microorganisms. Catena 27, 229-247.

Panebianco, J.E., Mendez, M.J., Buschiazzo, D.E., 2016. PM10 emission, sandblasting efficiency and vertical entrainment during successive wind-erosion events: a wind-tunnel approach. Boundary-layer meteorology 161, 335-353.

Van Pelt, R., Zobeck, T.M., 2007. Chemical Constituents of Fugitive Dust. Environmental Monitoring \& Assessment 130, 3-16.

Reynolds, R., Belnap, J., Reheis, M., Lamothe, P., Luiszer, F., 2001. Aeolian dust in Colorado Plateau soils: nutrient inputs and recent change in source. Proceedings of the National Academy of Sciences 98, 7123-7127.

Sanders, D., 1986. Desertification processes and impact in rainfed agricultural regions. Climatic change, 9: $33-42$.

Saxton, K., Chandler, D., Stetler, L., Lamb, B., Claiborn, C., Lee, B.-H., 2000. Wind erosion and fugitive dust fluxes on agricultural lands in the Pacific Northwest. Transactions of the ASAE 43, 631-640.

Schmidt, S., Meusburger, K., Figueiredo, T.D., Alewell, C., 2017. Modelling Hot Spots of Soil Loss by Wind Erosion (SoLoWind) in Western Saxony, Germany. Land Degradation \& Development 28, 1100-1112.

Shahabinejad, N., Mahmoodabadi, M., Jalalian, A., Chavoshi, E., 2019. In situ field measurement of wind erosion and threshold velocity in relation to soil properties in arid and semiarid environments. Environmental 
Earth Sciences 78, 501-523.

Skidmore, E., Powers, D., 1982. Dry soil-aggregate stability: Energy-based index. Soil Science Society of America Journal 46, 1274-1279.

Spagnuolo, V., Giordano, S., Perez-Llamazares, A., Ares, A., Carballeira, A., Fernandez, J., Aboal, J., 2013. Distinguishing metal bioconcentration from particulate matter in moss tissue: Testing methods of removing particles attached to the moss surface. Science of the total environment 463, 727-733.

Sullivan, D.A., Ajwa, H.A., 2011. Evaluation of wind erosion emissions factors for air quality modeling. Soil Science Society of America Journal 75, 1285-1294.

Sun, L., Chang, X., Yu, X., Jia, G., Chen, L., Liu, Z., Zhu, X., 2019. Precipitation and soil water thresholds associated with drought-induced mortality of farmland shelter forests in a semi-arid area. Agriculture, Ecosystems \& Environment 284, 106595.

Sweeney, M.R., McDonald, E.V., Etyemezian, V., 2011. Quantifying dust emissions from desert landforms, eastern Mojave Desert, USA. Geomorphology 135, 21-34.

Tatarko, J., Kucharski, M., Li, H., Li, H., 2020. PM2.5 and PM10 emissions by abrasion of agricultural soils. Soil and Tillage Research 200, 104601.

Tatarko, J., Wagner, L., Fox, F., 2019. The wind erosion prediction system and its use in conservation planning. Bridging Among Disciplines by Synthesizing Soil and Plant Processes 8, 71-101.

Tian, K., Wu, Y., Zhang, H., Li, D., Nie, K., Zhang, S., 2018. Increasing Wind Erosion Resistance of Aeolian Sandy Soil by Microbially Induced Calcium Carbonate Precipitation. Land Degradation and Development 29, 4271-4281.

Whicker, J.J., Pinder, J.E., Breshears, D.D., 2006. Increased wind erosion from forest wildfire: implications for contaminant-related risks. Journal of Environmental Quality 35, 468-478.

Wiggs, G., Holmes, P., 2011. Dynamic controls on wind erosion and dust generation on west-central Free State agricultural land, South Africa. Earth Surface Processes and Landforms 36, 827-838.

Xie, Z., Liu, Y., Hu, C., Chen, L., Li, D., 2007. Relationships between the biomass of algal crusts in fields and their compressive strength. Soil Biology and Biochemistry 39, 567-572.

Zhang, J., Zhang, C., Ma, X., Zhou, N., Wang, H., Rissler, P.S., 2014. Dust fall and biological soil crust distribution as indicators of the aeolian environment in China's Shapotou railway protective system. Catena 114, 107-118.

Zhou, C., Yang, F., Mamtimin, A., Huo, W., Liu, X., He, Q., Zhang, J., Yang, X., 2020. Wind erosion events at different wind speed levels in the Tarim Basin. Geomorphology 369, 107386.

Zobeck, T.M., Baddock, M., Scott, V., Tatarko, J., Acosta-Martinez, V., 2013. Soil property effects on wind erosion of organic soils. Aeolian Research 10, 43-51.

Zobeck, T.M., Van Pelt, R.S., 2006. Wind-induced dust generation and transport mechanics on a bare agricultural field. Journal of Hazardous Materials 132, 26-38.

Zou, X., Li, J., Cheng, H., Wang, J., Zhang, C., Kang, L., Liu, W., Zhang, F., 2018. Spatial variation of topsoil features in soil wind erosion areas of northern China. Catena 167, 429-439.

\section{Hosted file}

Table. docx available at https ://authorea. com/users/348926/articles/548852-threshold-analysisof-particulate-matter-emissions-from-biological-soil-crusts-and-their-proportion-intotal-wind-erosion

\section{Hosted file}


declaration-of-competing-interests.docx available at https://authorea.com/users/348926/ articles/548852-threshold-analysis-of-particulate-matter-emissions-from-biological-soilcrusts-and-their-proportion-in-total-wind-erosion

\section{Hosted file}

cover letter.docx available at https://authorea.com/users/348926/articles/548852-thresholdanalysis-of-particulate-matter-emissions-from-biological-soil-crusts-and-theirproportion-in-total-wind-erosion
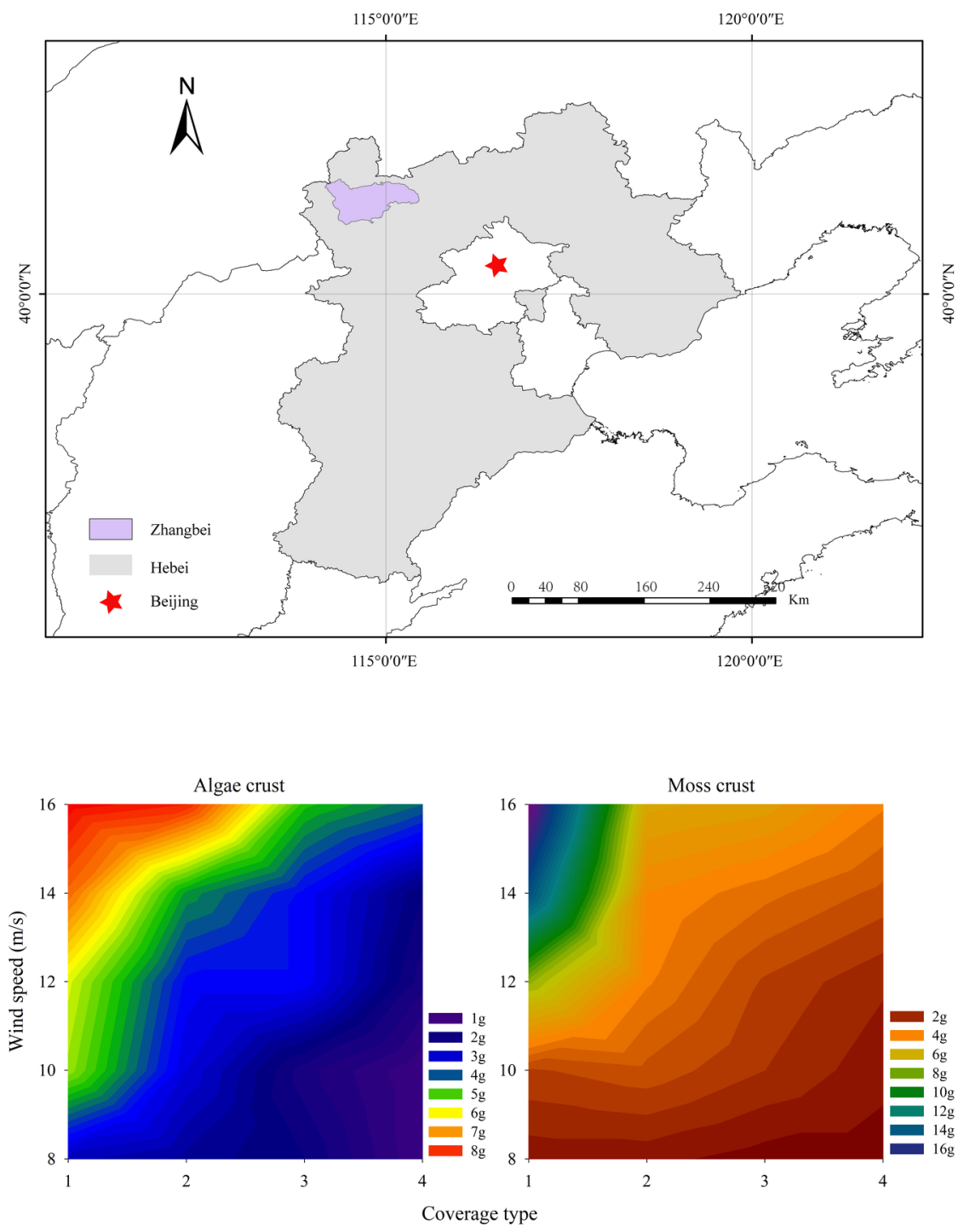
TSP

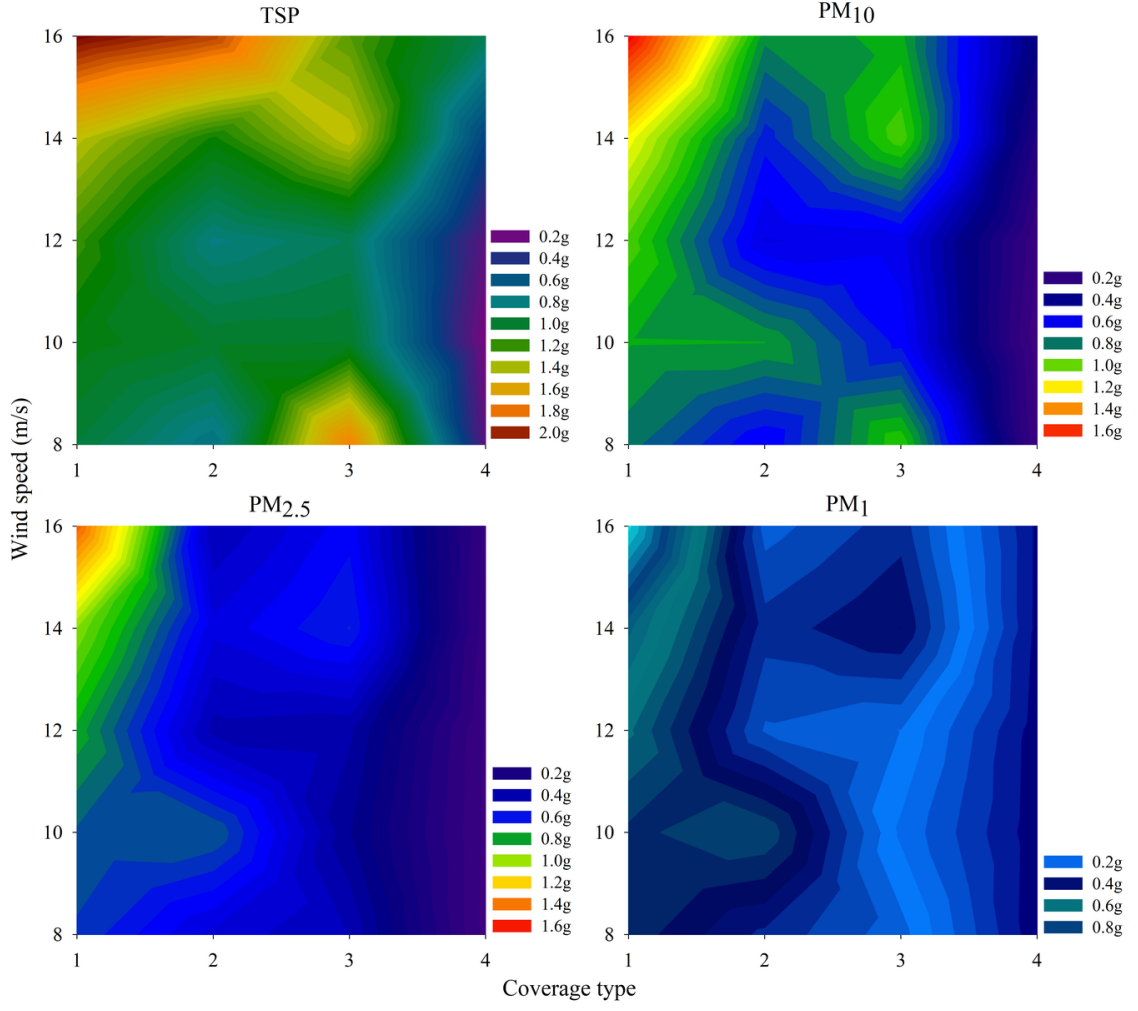

TSP

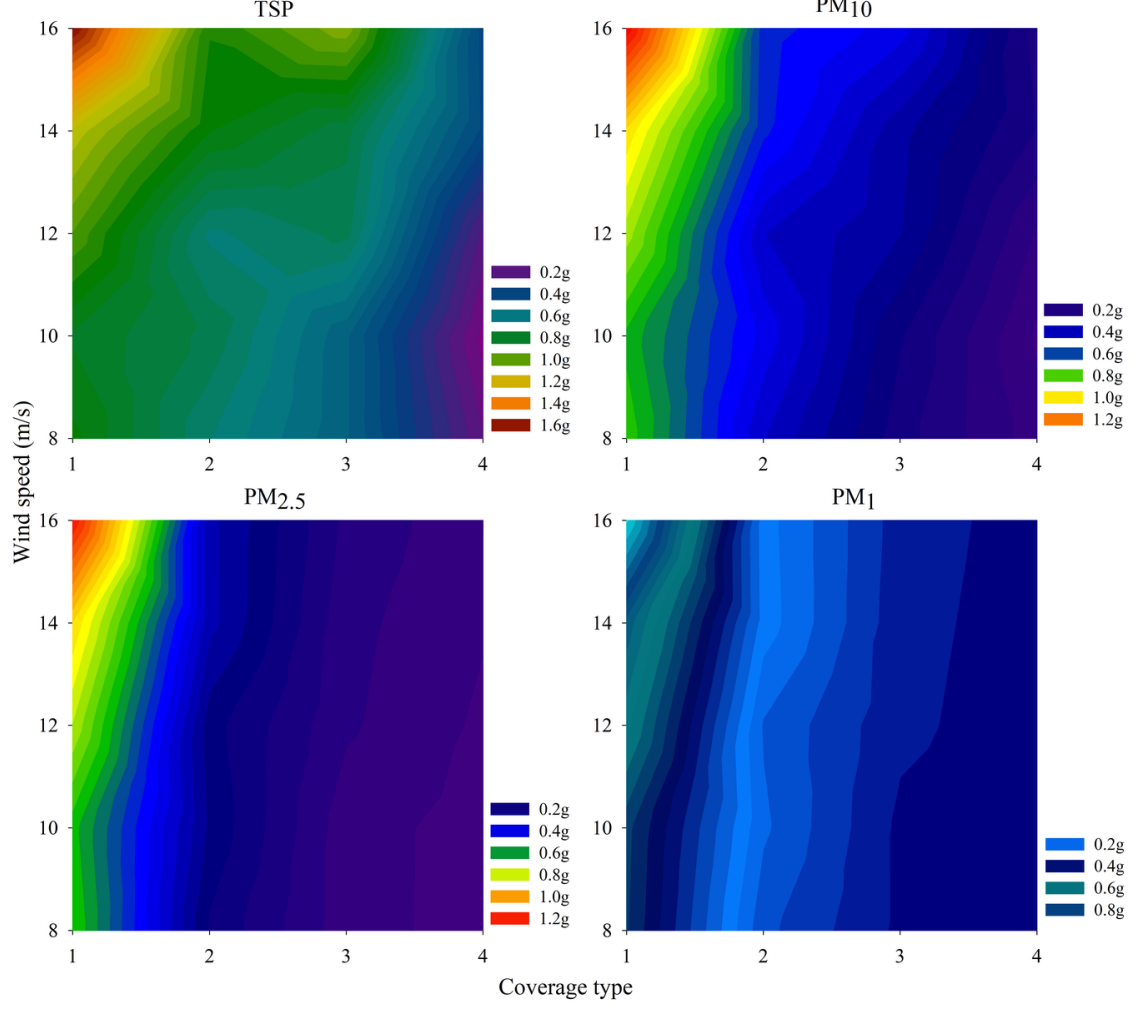



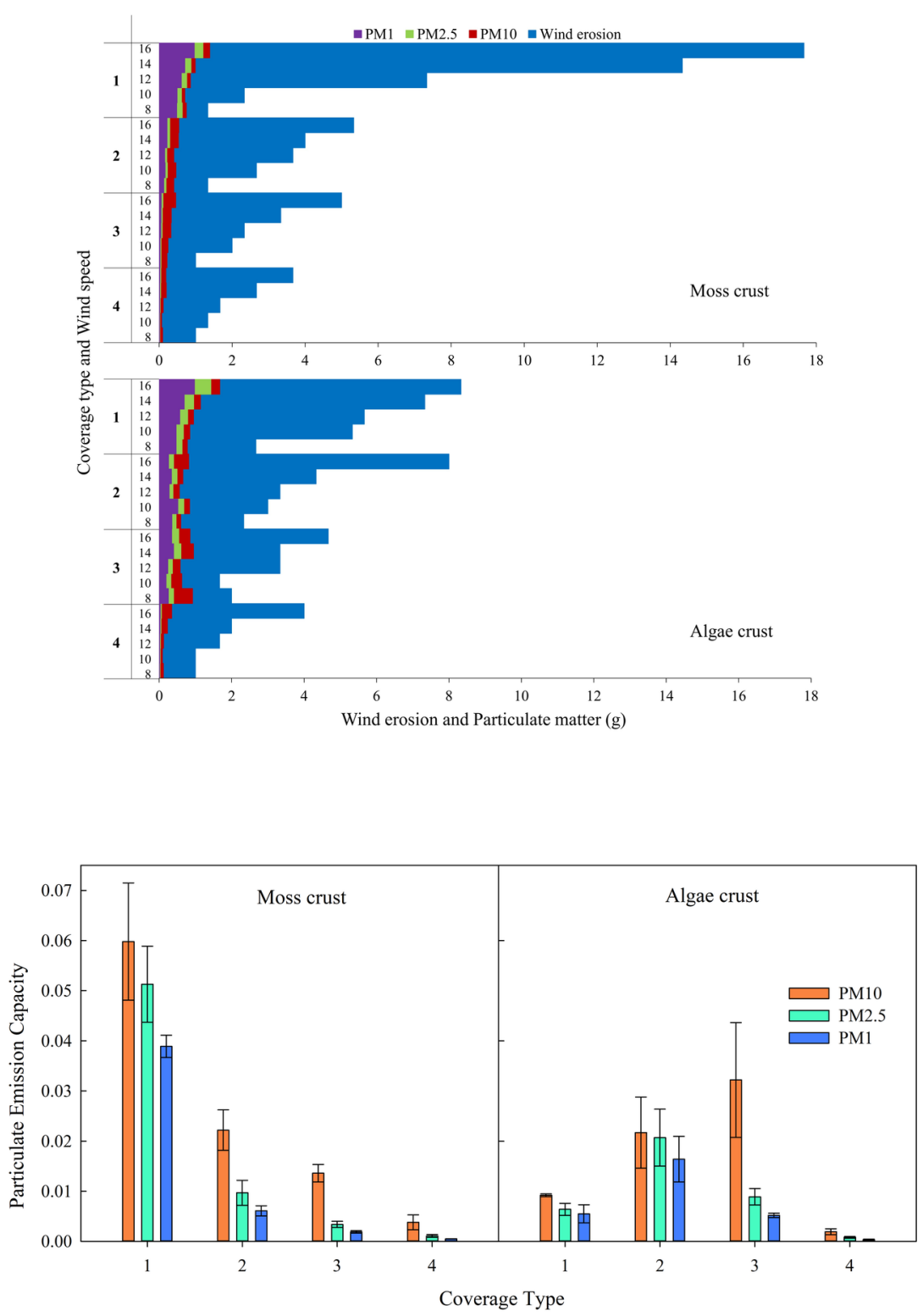


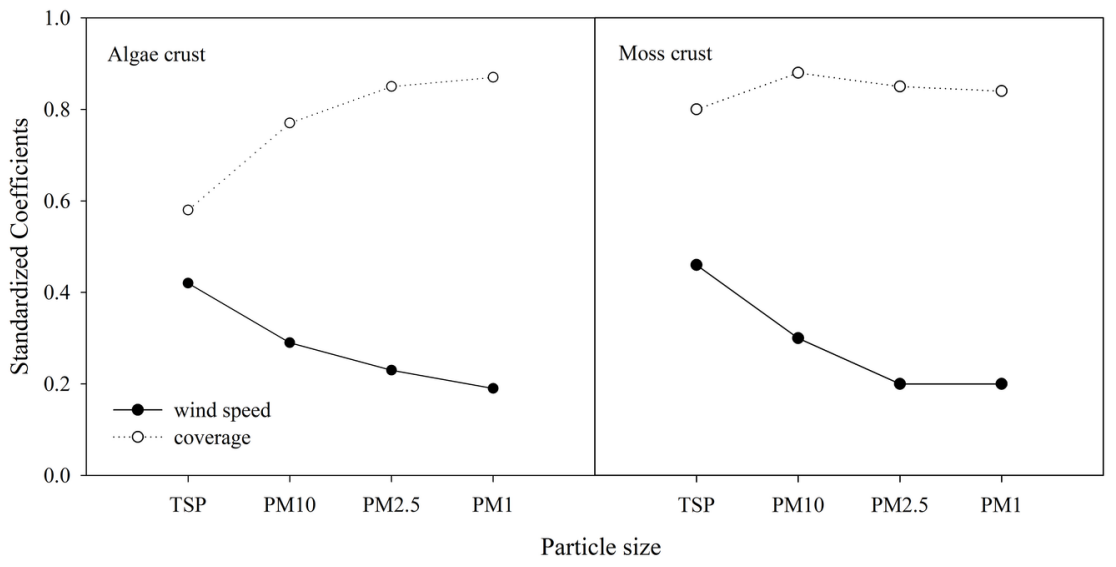

